\title{
IDENTIDADE SOCIAL EM MOVIMENTO: A COMUNIDADE JAPONESA NA GRANDE VITÓRIA (ES)
}

\author{
Joyce Rumi Suda \\ Lídio de Souza \\ Universidade Federal do Espirito Santo
}

\begin{abstract}
RESUMO: O presente trabalho objetivou identificar a identidade social de japoneses residentes na Grande Vitória (ES) a partir de informações sobre o próprio grupo e suas relações cotidianas, verificando-se também a existência de indícios de preconceito ou de tratamento discriminatório. Participaram da pesquisa 20 sujeitos, japoneses ou descendentes, de ambos os sexos, jovens e adultos. Os dados foram coletados através de entrevistas que exploraram os seguintes temas: namoro e conjugalidade, padrões estéticos, preconceito e estereótipo, identidade social e adaptação. Os resultados indicaram a existência de semelhanças e diferenças no que diz respeito à identidade do japonês capixaba, definida através da comparação com as características identitárias de japoneses de outros Estados.
\end{abstract}

PALAVRAS-CHAVE: imigração japonesa; adaptação; identidade social; preconceito.

\section{SOCIAL IDENTITY IN MOTION: THE JAPANESE COMMUNITY AT THE GREATER VITÓRIA AREA (ES)}

ABSTRACT: The objective of the present work was to identify the social identity of Japanese residents in the Greater Vitória area (State of Espírito Santo, Brazil), from discourses about the group itself and its everyday relations, also verifying the existence of indications of prejudice or discriminatory treatment. Twenty subjects, Japanese or descendants, from both sexes, young and adult, participated in the research. Data was collected through interviews that explored the following themes: dating and conjugality, aesthetic patterns, prejudice and stereotype, social identity and adaptation. The results indicated the existence of similarities and differences with respect to the identity of Capixaba Japanese (Capixaba being the designation of people from Espírito Santo state), defined through comparison with the identitarian characteristics of Japanese in other states.

KEYWORDS: Japanese immigration; adaptation; social identity; prejudice.

O ano de 1908 marca a chegada dos imigrantes japoneses ao Brasil pelo Porto de Santos. O navio Kasato Maru trouxe em torno de 165 famílias para trabalharem em fazendas de café em São Paulo (Saito, 1980). Os primeiros imigrantes tiveram muitas dificuldades de adaptação ao clima, à alimentação e às doenças tropicais e "(...) devido aos seus diferentes costumes e traços físicos", foram considerados os mais inassimiláveis dos estrangeiros (Ocada, 2000, p. 1). As diferenças culturais em relação a outros imigrantes eram tão profundas que criavam barreiras e acabavam por se cristalizar em forma de estereótipos e preconceitos. Apesar disso, havia uma intenção objetiva destes imigrantes em criar uma imagem de ordeiros, orgulhosos, fortes, trabalhadores e cordiais (Ennes, 2001).

As preocupações oficiais com a expansão da imigração japonesa eram de tal ordem que culminaram com a aprovação de uma emenda constitucional, em 1934, que restringiu a entrada a $2 \%$ do total de imigrantes que haviam sido admitidos no país durante os últimos 50 anos (Wakisaka, 1989). Na década de 1930 a política eugenista, defendida principalmente por psiquiatras, chegou a afirmar que os japoneses possuíam uma degenerescência racial inata. Eram biologicamente incompatíveis com outras raças, possuíam padrões morais, estéticos e econômicos diferentes, eram portadores de psicopatias e tendências criminosas e teriam um plano conspiratório de conquistar o mundo, sendo denominados na época de "perigo amarelo". Além disso, considerava-se que eram avessos à miscigenação, o que reforçava o medo relacionado à nação japonesa imperialista, em crescente expansão (Nucci, 2000).

Em vários momentos da história da imigração, fica clara a ameaça associada ao grupo, caracterizando um processo de diferenciação inter-grupal, que pode ser tão acentuado a ponto de provocar a despersonalização ou desumanização de membros de out-groups (Tajfel, 1983). O grupo foi identificado como não humano ou subumano e os japoneses e seus descendentes foram comparados a animais e insetos, a um vírus nocivo que invade a nação adoecendo-a, e a elementos químicos como o enxofre, que é insolúvel. Ocorreu também a demonização do grupo referindo-se a ele como mal, trevas e ódio (Nucci, 2000).

Mudanças no comportamento e no vestuário foram estratégias de inclusão utilizadas pelos japoneses, visando apagar diferenças que possibilitariam a expressão do ra- 
cismo, passando então a serem vistos como grupo migratório desejável. Outras estratégias de inserção social foram os casamentos interétnicos e as mudanças da aparência através das cirurgias plásticas para se tornarem "mais brasileiros" (Lesser, 2001).

Após a Segunda Guerra Mundial, começou uma nova etapa para os japoneses no Brasil, onde se verificou uma inserção social maior entre os brasileiros e uma maior condescendência em relação às uniões interétnicas, antes consideradas indesejáveis pelos membros da comunidade nipônica. Embora o processo de aculturação exerça pressão para a adaptação à nova cultura, reorientando pensamentos e sentimentos (Siqueira, 2005), os próprios descendentes se autodenominam "japoneses", visto que na sociedade brasileira a caracterização racial se faz através de traços físicos (Oliveira, 1998).

No que se refere ao Estado do Espírito Santo, a data da chegada dos primeiros japoneses é bastante imprecisa e as fontes consultadas mencionam as mais diferentes da-tas: 1923 (Associação Nikkei de Vitória, 1984), 1930 (Japo-neses relembram a imigração, 1999) e 1950 (Vitória será vista com outros olhos, 1974). Até o final da década de 1990, a comunidade era estimada em cerca de 200 a 350 famílias, já existindo no Estado membros até da sexta geração. Todos os dados encontrados informam um pequeno número de japoneses e seus descendentes no Estado do Espírito Santo quando comparados aos 3.097.232 de habitantes do solo capixaba. No Censo 2000, o IBGE informou que a população residente no Estado por cor ou raça era estimada em 3.056 amarelos, 1.512 .200 brancos, 200.192 pretos, 1.354.142 pardos e 12.746 indígenas. Os japoneses e seus descendentes estão concentrados na Grande Vitória, principalmente em Vitória e Vila Velha, informações semelhantes às do Censo 1991.

Na década de 1970, os japoneses já estavam bem instalados e adaptados em São Paulo, mas ainda eram novidade para os capixabas:

Esse sujeito de costumes esquisitos; que não tem jeito da gente distinguir dos seus patrícios - pois todos têm a mesma cara; que é humilde e prestativo, bom vizinho, gente; que já é uma parte do folclore de várias regiões brasileiras; que passará a fazer parte da paisagem capixaba, a partir da implantação da siderúrgica de Carapina (Presença amarela, 1982, p.32).

A reportagem destaca ainda a grande disposição para o trabalho, a mania de fotografar e a generosidade como empresários, ressaltando tanto a homogeneidade física, quanto a cultural. A imagem dos japoneses já estava construída antes mesmo da sua chegada em maior quantidade, imagem bem diferente do início da imigração para o Brasil.
Para a Associação Nikkei de Vitória (1984), muitos migraram inicialmente para o cultivo de hortaliças nos municípios da Serra, Afonso Cláudio, Viana, Mimoso do Sul e Cachoeiro de Itapemirim, mas falharam nos negócios e retornaram às cidades de origem. Segundo Morandi (1997), no final da década de 1970 e início da década de 1980, grande número de japoneses se deslocou para o Estado motivado pelo surto desenvolvimentista industrial, representado principalmente pela Companhia Siderúrgica de Tubarão (CST), que tinha como um dos principais acionistas uma empresa japonesa. Outras empresas de origem japonesa foram atraídas para a região e, a partir daí, muitos japoneses e descendentes migraram espontaneamente, constituindo a comunidade atual, com características notadamente diferentes das comunidades de São Paulo e Paraná, dedicadas inicialmente, principalmente, à agricultura.

Em 1981 foi criado o "Sunday Club", hoje chamada "Associação Nikkei de Vitória", que tinha a finalidade de promover o ensino de japonês e também atividades culturais e esportivas (Associação Nikkei de Vitória, 1998). Houve a necessidade de criar essas instituições para vencer a barreira da língua, da convivência com um povo ainda "estranho" e do clima muito diferente. Essa comunidade tinha como rotina ir do trabalho para casa e, nos finais de semana para a associação, mantendo-se isolada, principalmente devido às dificuldades com a língua portuguesa. Essas dificuldades vivenciadas durante o processo de migração contribuíram para o fechamento em uma associação, o que, por outro lado, “(...) favorece a criação de redes de solidariedade, facilita o acesso do 'estrangeiro' aos bens e serviços, apesar da discriminação(...)", criando espaços de resistência e aconchego (Sawaia, 2001, p. 125).

A cultura, os costumes e as tradições japonesas já fazem parte da vida cotidiana capixaba. Se antes da década de 1970 "apenas uma meia dúzia de japoneses ou descendentes estavam integrados na paisagem nativa" (Presença Amarela, 1982, p.10), após a instalação de diversas empresas com capital japonês, já havia cerca de três mil japoneses e descendentes no Estado, conforme o Censo 2000.

Embora o processo migratório dos japoneses e seus descendentes no Brasil tenha contribuído para a constituição de um grupo com características compartilhadas, relacionadas à mesma origem étnica - estudioso, trabalha-dor e disciplinado -, o processo de aculturação também incorporou as características regionais e locais. Podemos verificar que, a par das características compartilhadas, características regionais e locais contribuem para diferen-ciar os japoneses uns dos outros. Os nipo-capixabas, por exemplo, são considerados mais tranqüilos, mais fechados e mais "normais" -, e formam um grupo com identidade diferenciada, foco do presente trabalho. 


\section{Identidade Social}

Segundo Hogg, Abrams, Otten e Hinkle (2004), temos tantas identidades sociais e pessoais quanto são os grupos aos quais pertencemos, mas apenas uma identidade é psicologicamente real em dada situação. As identidades mudam em resposta a mudanças contextuais, e a forma como os membros de um grupo se auto-definem depende da comparação com outros grupos. Podemos dizer que as comparações sociais individuais e grupais são fundamentais para a definição de si próprios, de sua pertença a um grupo e da sua influência social.

Tajfel (1983) conceitua identidade social a partir das relações grupais: "A identidade social será entendida, (...) como aquela parcela do auto-conceito dum indivíduo que deriva do seu conhecimento, da sua pertença a um grupo (ou grupos) social, juntamente com o significado emocional e de valor associado àquela pertença" (p.290).

Tajfel (1983) afirma também que no processo de comparação social existe uma tendência a atribuir valoração negativa ao out group e positiva ao in group, o que não significa que um indivíduo não possa ter uma identificação problemática com o próprio grupo. Se um grupo não oferece condições adequadas para preservar uma identidade social positiva, pode-se optar pela estratégia da mobilidade social ou de mudança para um de status mais alto, "desidentificando-se" com o grupo original. Este processo pode ser identificado na constatação de que alguns nikkeis preferem se relacionar quase que exclusivamente com brasileiros, muitas vezes sem qualquer contato com outros japoneses, identificando-se com o grupo que não é o de origem.

Há casos, porém, em que os indivíduos não são aceitos pelo grupo dominante e são também rejeitados pelo próprio grupo, pois se considera que traíram sua identidade. É o caso de nipo-brasileiros que tentaram negar de forma mais veemente a cultura de origem, e provocaram reações negativas na comunidade nipônica (Lesser, 2001). Ao mesmo tempo, não são completamente aceitos como brasileiros, são assim tratados apenas nas relações estabelecidas com japoneses (Camacho, 1993).

A rejeição e o preconceito são tipos de defesa contra aqueles que se apresentam como ameaça ao nosso modo de vida e à nossa posição social, ou seja, à nossa identidade (Tajfel, 1983). Sendo assim, certas características identitárias dos japoneses, inicialmente tidas como positivas, podem funcionar também como mecanismos de discriminação e exclusão social, dependendo do contexto em que são aplicadas.

Como diz Ennes (2001), partindo da idéia de "identidade inacabada", os imigrantes e seus descendentes estão em processo dinâmico e ininterrupto de construção e desconstrução de identidades étnico-culturais. Incorporam práticas originariamente estranhas, ao mesmo tempo em que insistem na manutenção de determinados aspectos da cultura do grupo de origem, instituindo uma área de intersecção entre os grupos.

Considerando a escassez de estudos sobre a comunidade nipo-brasileira residente na região da Grande Vitória -ES, o presente estudo procurou conhecer as características que compõem a identidade social de japoneses e descendentes residentes na localidade, bem como as características identitárias por eles atribuídas aos capixabas.

\section{Método}

\section{Participantes}

A pesquisa foi desenvolvida em dois momentos: 1) no primeiro momento, foi realizado um estudo com 22 japoneses ou descendentes, de ambos os sexos, jovens e adultos, visando obter informações gerais sobre a manutenção da cultura japonesa, a percepção de discriminação e preconceito nas relações sociais e a adaptação do grupo, através da aplicação de questionários. Os questionários foram aplicados em participantes conhecidos dos pesquisadores ou não e que, na maioria dos casos, estavam presentes na Associação Nikkei de Vitória nos dias em que a instituição foi visitada. O único critério utilizado foi ser japonês ou descendente; 2) no segundo momento, optou-se por excluir 2 participantes, que possuíam uma percepção ambígua em relação à discriminação contra japoneses ou descendentes. $\mathrm{O}$ grupo de participantes foi composto por 13 pessoas do sexo feminino, dentre os quais 9 mulheres jovens e 4 mulheres adultas e 7 participantes do sexo masculino, 4 homens jovens e 3 homens adultos. A idade dos jovens variou entre 17 e 23 anos e a idade dos adultos entre 49 e 58 anos.

Neste grupo, 17 pessoas eram pertencentes à Associação Nikkei de Vitória e 3 pessoas não tinham vínculo com a mesma. Alguns dos participantes possuem vínculos familiares como pai e filha, mãe e filho, irmãs e outros sem qualquer grau de parentesco entre si. Apenas seis entrevistados, todos jovens, nasceram no Espírito Santo.

A maioria dos jovens tinha curso superior completo ou em andamento, e alguns deles estavam cursando pósgraduação. Entre os 7 adultos, apenas 2 não tinham curso superior, um dos quais havia começado o curso de Economia, mas não completou. Nenhum dos jovens tinha vínculo empregatício no período da pesquisa, apesar de colaborarem informalmente com seus pais em negócios próprios. Todas as mulheres adultas eram donas-de-casa, porém ocupavam parte do seu tempo estudando ou colaborando nas atividades da Associação Nikkei. Entre os homens adultos, todos trabalhavam em grandes empresas ou tinham negócio próprio.

Estiveram representados no grupo de participantes quatro gerações ${ }^{1}$ de descendentes: 3 isseis (japoneses nascidos no Japão que vieram morar no Brasil, primeira geração), 9 nisseis (filhos de japoneses, segunda geração), 6 
sanseis (netos de japoneses, terceira geração) e 2 yonseis (bisnetos de japoneses, quarta geração). Consideramos que "japonês" designa qualquer pessoa com ascendência japonesa, independentemente de ser nascido no Brasil.

\section{Instrumento}

$\mathrm{O}$ instrumento utilizado para a coleta de dados foi a entrevista semi-estruturada. Os tópicos da entrevista constaram de uma primeira parte com dados pessoais, caracterizando o participante por sexo, escolaridade, idade, parentesco com japoneses, profissão, estado civil e local de nascimento. A segunda parte, com questões abertas, possuía um roteiro focalizando os seguintes temas: breve histórico da chegada e fixação no Estado, identidade social dos japoneses, representações que possuem dos brasileiros e dos capixabas, avaliação do acolhimento pelos capixabas, relacionamentos interétnicos (conjugais e de amizade) e existência e funcionalidade de uma associação que visa à manutenção da cultura de origem.

\section{Procedimentos}

Utilizando a listagem dos participantes do primeiro momento da pesquisa, fizemos contato com vinte participantes, convidando-os a participar do segundo momento, abordando o tema comunidade japonesa no Espírito Santo. Marcamos o encontro individualmente em local de preferência dos participantes, ocasião em que foi feita uma breve explicação sobre a pesquisa, esclarecendo que teriam tempo livre para responder as questões propostas. Após a aceitação, apresentamos o Termo de Consentimento Informado para ser assinado, termo que garante sigilo absoluto sobre sua identidade pessoal. Solicitamos também autorização para a utilização do gravador.

Na análise dos dados, utilizamos a Técnica de Análise Temática (Bardin, 1977/1994) para a decomposição, classificação e descrição do conteúdo das entrevistas, de acordo com o seguinte procedimento: tomando como referência os núcleos de interesse contidos no roteiro da entrevista, foram elaboradas categorias que serviram de base para a decomposição das entrevistas e posterior reagrupamento. Neste artigo, optamos por apresentar apenas os resultados relacionados à identidade nipo-brasileira no contexto capixaba.

\section{Resultados e Discussão}

\section{Características atribuídas aos japoneses em geral}

De acordo com Kitahara (1998), a organização social hierárquica do Japão formou uma população obediente, dedicada ao trabalho e ao estudo, que não gosta de quebrar regras e é conformista, deixando de herança para as novas gerações dos imigrantes japoneses, características tais como timidez, modéstia, sinceridade, honestidade e esforço no trabalho e nos estudos. Camacho (1993) conclui que
(...) o japonês é disciplinado, circunspecto, austero e rígido no cumprimento de seus deveres porque sua vida possui como eixo, a vergonha e o cultivo da honra ao nome, à família e à nação. A exigência extremada de si próprio nasce do temor ao ostracismo, à difamação e à rejeição. Ele não vive para o bem e fugindo do mal. Ele vive, isto sim, no interior dos círculos, sendo enredado pelas obrigações. Assim é o japonês (p.54).

As características lembradas pelos participantes foram: estudioso e esforçado, trabalhador e honrado, disciplinado e organizado, tímido e sensível, conservador e submisso, falso e machista, algumas características físicas e outras que não puderam ser agrupadas nas categorias. Estas características são semelhantes às citadas nos trabalhos acima.

A maioria dos participantes se identifica, por vezes, com brasileiros e, por vezes, com japoneses, utilizando pronomes retos como nós e eles para se referir ao mesmo grupo em diferentes momentos da entrevista, dependendo do contexto que favoreça uma identificação positiva com um ou outro grupo.

Lesser (2001) enfatiza que, no processo de assimilação, a cultura pré-imigratória tenderia a desaparecer por completo - fenômeno raro -, enquanto no de aculturação ocorreria a modificação de uma cultura em contato com outra, o que foi bastante comum mesmo para os japoneses que viviam em comunidades fechadas. Por esse processo é possível ocorrer o reconhecimento de si próprio nos dois grupos, a partir de características de origem que foram mantidas e características agregadas ou modificadas da cultura receptora. Willems (1940, citado em Nucci, 2000), associa o conceito de assimilação a mudanças na esfera social e o conceito de aculturação a mudanças na esfera cultural. Afirma que a mobilidade social, a escola brasileira e a inexistência de templos religiosos japoneses no Brasil são fatores aculturativos.

Kiefer (1974, citado por Yamamoto, 2000), fornece dois conceitos de aculturação: linear, em que o imigrante tem que abdicar de parte da sua cultura de origem, e não linear em que o imigrante não precisa necessariamente deixar a cultura, sendo esta inserção livre e por conveniência. Cita ainda Oguri-Kendis (1989), que afirma que a aculturação não exclui a manutenção da cultura japonesa em diferentes graus e Masuda e Matsumoto (1970), que afirmam que o grau de aculturação está em relação inversa à orientação étnica, ou seja, quanto maior o grau de aculturação, menor a orientação étnica. No nosso trabalho, fica claro que a aculturação é forte nas gerações mais novas, assim como encontrado por Inamura (1981, citado em Yamamoto, 2000), justificado no desconhecimento da língua japonesa e no comportamento como o dos brasileiros. Pudemos verificar que as gerações mais novas - já melhor adaptadas - pressionam as gerações anteriores, sugerindo a adoção de comportamentos e mo- 
dos de pensar mais flexíveis e mais de acordo com a cultura brasileira. Observamos uma pequena diferença entre os participantes da pesquisa de Camacho (1993) para os quais o lazer não era valorizado. A preservação da cultura de origem era mais forte no início da imigração, facilitada pela concentração em comunidades, tanto no Brasil quanto no Espírito Santo. Hoje, com o desenvolvimento de gerações mais integradas à cultura receptora, a manutenção da cultura de origem é mais difícil e complexa.

Lesser (2001), Oliveira (1998), Ennes (2001) e Yamamoto (2000) informam que a identidade social fica em xeque principalmente quando vão ao Japão, ocasião em que os nipo-brasileiros se sentem sem nacionalidade. No Brasil, mesmo que queiram se tornar brasileiros completos, não são reconhecidos como tais, e no Japão também se sentem como estrangeiros. Os traços físicos condicionam a alteridade em relação aos não nipo-brasileiros.

Observamos que ainda ocorre a reprodução de alguns valores tradicionais japoneses na comunidade japonesa do estado, o que ajuda na integração e na ascensão social do grupo, assim como ocorreu em outros estados no Brasil (Ennes, 2001). Associando estas características japonesas a outras referentes à identidade brasileira, constituem uma nova identidade em processo de construção contínua. Desta forma, o indivíduo mantém uma auto-estima positiva que é alcançada a partir da identificação com mais de um grupo.

Eu acho que os japoneses daqui hoje... não é igual aos japoneses mesmo... e os japoneses mesmo, mesmo né, eu acho que eles são mais frios (Homem Adulto 1).

(...) porque a gente tá acostumada a ter uma família estruturada, a ter um padrão financeiro, a ter prioridade que normalmente a maioria das famílias de gente aqui fora não tem. Tipo, a gente confia demais no estudo né, no, no valor que o estudo vai trazer pra vida da gente (Mulher Jovem 3).

Dá pra sentir até um ET assim na rua... parece que eu sou um ser de outro lugar, parece que eu não sou brasileira, parece que eu não, não conheço nada daqui, não, como se diz, não, não tô inserida na cultura daqui, parece que eu sou um ser de fora (Mulher Jovem 9).

\section{Características atribuídas à comunidade japonesa da Grande Vitória}

$\mathrm{Na}$ pesquisa de Inoue (2002) foram encontrados dados sobre caracterização dos dekasseguis de acordo com o Estado em que moravam no Brasil. Seus entrevistados afirmam que os japoneses de São Paulo são mais "atirados" que os do Rio de Janeiro, que ao contrário, seriam mais passivos ou considerados mais "puxa-sacos". De acordo com o relato dos japoneses cariocas, os paulistas não seriam tão sérios, "aprontando" muito em seus ambientes de trabalho com seus colegas japoneses. Uma das suas entrevistadas relata que paulistas e paranaenses tratavam de maneira diferente os cariocas, que estavam em minoria na condição de dekasseguis, afirmando que eram melhores e mais determinados. $\mathrm{O}$ japonês carioca é apontado como "malandro", estereótipo de qualquer carioca. Como estavam em relação de competição pela manutenção do trabalho, tentavam arrumar mecanismos para prejudicar o outro, por exemplo, deturpando a tradução da língua japonesa no local de trabalho. Na clara situação de conflito configurada na competição pelo trabalho dos dekasseguis no Japão, os grupos se dividem pelo estado de proveniência, diferenciando-se positivamente, uns dos outros.

A comunidade japonesa de Vitória também se diferencia da dos demais estados. A principal diferença encontrada entre japoneses que moram em Vitória e japoneses que moram em São Paulo é a própria diferença de morar em cidade menor e cidade grande. Ou seja, os japoneses do Espírito Santo agem como os capixabas e os de São Paulo agem como os paulistas. Os entrevistados deram exemplos de como os japoneses de São Paulo, pertencentes ao out group, seriam mais estressados, mais metidos, mais arrogantes, entre outras coisas, demonstrando o reconhecimento de seu próprio grupo, assim como do outro grupo.

Os japoneses que moram no estado são considerados mais fechados porque visam a conservação das tradições que, no entanto, vêm se perdendo. Há queixas e, ao mesmo tempo, elogios quanto ao abrasileiramento da própria instituição responsável pela manutenção da identidade étnica. A comida japonesa já tem o tempero brasileiro e os descendentes de japoneses, principalmente os mais jovens, já não se interessam mais pela língua de origem, deixando clara a força do processo de aculturação. Além disso, entre os pesquisados, a maioria afirma não ter religião, e os jovens sequer conhecem os rituais religiosos japoneses e os objetos utilizados. Há alguns objetos tradicionais japoneses dentro das casas dos entrevistados, porém, em número reduzido.

Os que moram em São Paulo seriam mais abertos e receptivos aos brasileiros, embora também procurassem preservar as tradições. A grande quantidade de japoneses em São Paulo e toda a importante história da imigração no Estado acabam marcando uma diferença e valorizando a cultura de origem através do contato com outros japoneses e através de instituições como associações, museus, centros de estudos, bairros predominantemente japoneses e, por conseqüência, um maior número de eventos para sua divulgação e fortalecimento cultural. De acordo com os participantes, os moradores de São Paulo se sentiriam mais brasileiros por não serem apontados como diferentes, como ainda é o caso em Vitória. Muitos termos como "bicho diferente", "ET", "alienígena", 
"não é normal", foram utilizados pelos participantes para designar a diferenciação que é feita em relação aos japoneses em Vitória.

Todos consideram a Associação Nikkei de Vitória aberta a brasileiros no sentido literal da palavra, pois pode ser freqüentada por brasileiros. Porém, metade deles ainda acredita que existem restrições. Os jovens afirmam que principalmente por parte dos mais velhos ocorre uma diferença no tratamento dos brasileiros que freqüentam a instituição. No processo de aculturação de boa parte dos japoneses mais velhos acaba ocorrendo a rejeição de alguns valores da população hospedeira, o que dificulta os contatos sociais e o estabelecimento de novos laços (Mota, Franco \& Motta, 1999).

Alguns participantes declararam que a associação em Vitória é conservadora e tenta manter tradições que existiram somente na época em que imigraram para o país, e que não existem mais. A abertura é considerada bastante recente.

Talvez a diferença que pode existir é somente gerado por situação, quem mora na grande cidade e quem mora em Vitória que é uma coisa menor (Mulher Adulta 1).

(...) eles me parecem mais fechados e um pouquinho mais esnobes que os daqui, que parece que eles se sentem mais bem sucedidos que os daqui... você ter que, como é que fala, se esforçado mais pra sobreviver num ambiente mais complicado, te deu um pouquinho mais de, né, auto-estima (Mulher Jovem 3).

Acho que eles puxam muito o lado paulista né, paulista é mais metido, não sei o que, e realmente paulista, japonês de São Paulo é mais chato (Homem Jovem 1).

\section{Características atribuídas aos capixabas}

O capixaba é aquele que não é o paulista, não é o carioca, não é o baiano, como afirmado por alguns entrevistados que conseguem enxergar como os outros são, mas não conseguem caracterizar o grupo a que pertencem. Afirmam que os outros têm características específicas, ao contrário do capixaba, que é simplesmente "normal". Falam do capixaba como se não tivesse uma identidade, porque não há nada que o destaque, como citado por outro participante. Mas como Gama Filho (2003) bem diz:

a identidade cultural capixaba também não possui uma essência nítida: ela é o que as demais identidades não são. Sua característica mais exata é ser "o que as outras não são": a identidade cultural capi-xaba é aquela que não é a mineira, não é a baiana, não é a italiana - não é nenhuma das outras do seu sistema (Gama Filho, 2003, p.232).

A identidade resulta da diferença, portanto, da comparação, logo, a idéia de que o capixaba não tem uma identidade peca por ser superficial, pois o comparamos com habitantes de outros estados e percebemos que existem diferenças.
As características citadas para os capixabas foram: normal e comum, amigável, descontraído, tranqüilo, trabalhador e honrado, estudioso e esforçado, disciplinado e organizado, provinciano, pouco dedicado, e outras que não puderam ser agrupadas nas categorias. Percebemos que há mais características positivas lembradas do que negativas para os capixabas. É interessante observar que muitos japoneses se identificam com os capixabas quando é necessário compará-los a grupos de outros estados e, portanto, os qualificam positivamente. Por vezes, utilizam o pronome "nós" quando se referem aos capixabas, indicando a identificação com o grupo: "Espontâneos. A gente faz o que dá na telha” (Mulher Jovem 3).

Entre as características positivas, a mais citada foi "amigável" e a característica negativa mais lembrada foi "provinciano", que tem o significado principal de pouca abertura à diferença.

Porque as pessoas assim, cariocas, paulistas, que vem morar aqui, eles fazem comentários, né, que os capixabas são, são mais na deles assim, não são muito simpáticos. Mas eu não sei, não sei se é porque eu sou capixaba, eu não sinto essa diferença assim (Mulher Jovem 4).

Capixaba não, não, ele não sabe lidar muito assim com o diferente mesmo e eu digo isso não só com relação aos japoneses não, em escola assim... o menino que tem deficiência física, o negro, o japonês, o gay, tem muito discriminado aqui, eu acho que aqui o grau de preconceito com relação às coisas é muito grande (Mulher Jovem 9).

Como os japoneses acham que são vistos pelos brasileiros

A maioria dos entrevistados relata que ouve muitos elogios decorrentes da descendência, mais do que críti-cas, ou seja, são avaliados mais positivamente do que negativamente pelos capixabas. Isto pode ter ocorrido pelo fato de o grupo não tender a evidenciar coisas negativas sobre si mesmo (Tajfel, 1983), ou porque, de maneira geral, são reconhecidos mais pelas qualidades.

As características relatadas conforme acreditam ser a visão dos brasileiros foram semelhantes às que os próprios participantes acreditam ser as características dos japoneses: estudioso e esforçado, trabalhador e honrado, disciplinado e organizado, tímido e sensível, conservador e submisso, falso e machista, algumas características físicas, e outras que não compõem as categorias citadas. Muitos brasileiros elogiam os japoneses, principalmente na escola e no trabalho. A característica mais ouvida é "inteligente": "Eu acho, porque tudo o que você vê na escola sobre Japão fala bem. Com a tecnologia, os avanços, só isso que você ouve na escola" (Mulher Jovem 5). Porém, às vezes esta característica positiva provoca consequiências: 
(...) é um pré-julgamento que fala que nós somos inteligentes, mas é um pré-julgamento que pra eles é ruim... Fala que nós somos mais inteligentes, então eles acham que, acham inferiores (Homem Jovem 2).

Sentia que muitos invejavam assim, queriam ser japoneses só pra levar o nome de CDF, né. E eles, alguns me isolavam por causa disso, por eu ser japonesa e por, por ter essa fama de CDF (Mulher Jovem 1).

Alguns entrevistados relataram situações de exclusão na escola por serem considerados muito dedicados ao estudo ou por serem reconhecidos como bons funcionários nos ambientes de trabalho. Uma das entrevistadas afirma que no Brasil não se valoriza quem gosta de estudar, como acontece no Japão, e que era rejeitada pelos colegas que estavam "preocupados em namorar", sendo, muitas vezes, motivo de risada; outra relata a cobrança que havia por parte de alunos para que tirasse as melhores notas porque era “japonesa" e como a excluíam, deixandoa sozinha na escola; e ainda outra entrevistada era taxada de "velha" por se comportar de uma forma mais recatada quando "tinha que parecer gostosa", afirmando que os japoneses procuram não parecer vulgares, mas sempre inteligentes e interessantes. Verificamos, portanto, que pode ocorrer prejuízo nos relacionamentos interpessoais.

Alguns entrevistados percebem um ciúme (significa "inveja" pelo contexto utilizado pelos participantes) que os brasileiros teriam dos japoneses, pois os considerariam mais bem sucedidos e por isso estariam "tomando espaço". Argumento que justifica também a pixação no muro da USP, dizendo que para entrar no vestibular basta matar um japonês. Fica claro que existe a percepção de incômodo dos brasileiros, opinião também dividida com Camacho (1993). Alguns consideram uma forma de elogio, mas pode haver outras interpretações, por exemplo, quando Hilton (2004) deixa claro que, em um processo de comparação social, existe a tendência a colocar em patamar inferior - ou excluir de alguma outra maneira - aquele que ameaça a auto-estima de alguém, estereotipando-o. Neste caso, predominaria o estereótipo do japonês bitolado em estudo ou que é muito estressado porque trabalha e estuda demais.

O que se verifica é que, dependendo do contexto, características inicialmente tidas como positivas atribuídas aos japoneses podem se transformar em negativas, funcionando como mecanismo de discriminação e exclusão social. Como bem demonstra Tajfel (1983), o preconceito pode ser uma forma de defesa contra aqueles que se apresentam como ameaça ao nosso modo de vida e à nossa posição social.

\section{A adaptação dos japoneses no Espírito Santo}

Saito (1980) afirma que os japoneses estão bem adaptados ao contexto brasileiro, ressaltando a ausência de dis- criminação no país quando comparado a países como Estados Unidos e Peru, o que teria possibilitado uma grande diversificação ocupacional e os casamentos interétnicos.

Segundo reportagem da Revista Espírito Santo Agora (Presença Amarela, 1982), alguns japoneses moradores da Grande Vitória são considerados completamente adaptados, mesmo mantendo alguns costumes. Parece não ter havido muitos problemas de integração no estado devido à existência do Porto de Vitória, que permitiu a vinda constante, antes da década de 1950, dos marinheiros, comerciantes e técnicos japoneses, deixando boas impressões, de ser um povo sensível, humilde, gentil e trabalhador, apesar de retraído.

Por outro lado, a reportagem mencionava que as particularidades culturais - contrastes de hábitos, comportamentos e culturas heterogêneas - por vezes causaram atritos. Outra reportagem da mesma revista informa que a integração foi considerada difícil em função da pouca sociabilidade com brasileiros devida à herança de temperamento e cultura distintos e, por vezes, opostos aos ocidentais. Na época da implantação da CST, ainda havia o agravante da existência dos contratos temporários de vários trabalhadores, o que também afetava as relações com a comunidade capixaba. Após a ocorrência do chamado choque cultural (Sousa \& Santos, 1999) devido às diferenças culturais, às incertezas e o conseqüente estresse provocado pela migração, verificou-se o desenvolvimento progressivo da adaptação intergrupal para os que aqui permaneceram (Mota et al., 1999).

Os entrevistados acreditam que os japoneses estão bem inseridos e adaptados em diferentes graus no Espírito Santo. O indicativo mais comum para uma boa adaptação é a crença de que não há restrições para japoneses no estado e que são, portanto, tratados como qualquer outro, tendo acesso à escola, trabalho, lazer e relacionamentos. Alguns participantes afirmaram que em vários momentos esquecem que são japoneses. A grande quantidade de casamentos interétnicos, que vem aumentando a cada geração, principalmente a partir da década de 1970, contribui para uma integração maior na sociedade brasileira (Lesser, 2001; Saito, 1980). Nesta pesquisa verificamos que todos os jovens tiveram ou ainda têm maior envolvimento amoroso com brasileiros, o que não foi constatado entre os adultos (apenas um adulto entre os seis entrevistados):

(...) eu acho que já ficou natural, uma coisa normal assim... alguma pessoa deve sentir alguma coisa assim, deve ter restrição por japonês, mas é uma minoria assim (Mulher Jovem 1).

(...) na verdade eu acho que é completa porque não tem uma distinção, não tem nenhum preconceito (Homem Jovem 2). 
A recepção dos capixabas aos japoneses também é considerada boa pelos entrevistados, apesar do tamanho reduzido da comunidade. Alguns deles indicaram que brincadeiras e piadas relacionadas à etnia contribuem para a percepção de certa diferenciação que ainda é feita em relação ao seu grupo.

Dentro da normalidade, não é muito receptivo e, assim, aquela coisa de ficar perguntando e tal, não sei o que e rindo e, mas assim, os que eu conheço eles sentem curiosidade de saber e sentem vontade de tá convivendo com japoneses (Mulher Jovem 7).

\section{Considerações Finais}

Concluímos que a identidade social dos japoneses e de seus descendentes no Espírito Santo é a identidade do nipo-brasileiro, ou seja, apresenta traços tanto da cultura de origem, como traços brasileiros, porém o que os identifica como grupo é a origem étnica. Verificamos, porém, a existência de in e out groups (Tajfel, 1983) nas várias relações inter-grupais estabelecidas e a existência de subdivisões internas ao grupo dos japoneses, ou seja, ocorre a avaliação das categorias sociais de maneira diferenciada: entre japoneses e brasileiros; entre nipo-brasileiros e japoneses do Japão; entre japoneses capixabas e paulistas; entre nipo-brasileiros mais abrasileirados e nipo-brasileiros mais tradicionais; entre mestiços e "japoneses puros". A noção de pertencimento ao grupo dos japoneses que moram no Espírito Santo fornece critérios para julgamento de outros grupos e permite a flexibilidade da identidade social: sentem-se pertencendo ao grupo dos japoneses em determinados momentos e, em outros, ao grupo dos brasileiros, dependendo do contexto e dos grupos que estão sendo comparados.

O sentimento de pertencimento a um grupo social ocorre na comparação social com outros grupos, mas "mudam" de identidade social de acordo com a situação colocada, evidenciando outra característica fundamental da identidade como processo: a flexibilidade (Tajfel, 1983). Sentem-se japoneses em comparação com os brasileiros, sentem-se nipo-brasileiros em comparação com japoneses, sentem-se capixabas em comparação com os paulistas.

Essa identidade nipo-brasileira não é vivida sem crises, visto que é uma identidade não reconhecida pelos brasileiros. A denominação "japonês" revela a identidade atribuída a qualquer descendente, e a ela estão associadas várias exigências: quando seguem à risca o estereótipo do japonês, surgem críticas por serem "muito japoneses", sugerindo que sejam mais flexíveis em sua conduta; quando procuram se pautar pelas regras culturais e de comportamento dos brasileiros, são pressionados a serem "mais japoneses".
Verificamos que, de forma geral, o próprio grupo é representado positivamente pelos participantes, pois na maior parte das vezes são ressaltadas características positivas, ligadas principalmente ao estudo e ao trabalho, corroborando as conclusões de Camacho (1993), que afirma que a educação é responsável pela discriminação positiva dos nipo-brasileiros. As características negativas que surgiram para o próprio grupo têm ligação com o comportamento rígido, com a disciplina e com a hierarquia, que nunca foram avaliados como pertencendo a si próprios.

Existe certo antagonismo entre as características atribuídas aos nipo-brasileiros e aos capixabas: enquanto um dá valor ao estudo, o outro é muito despreocupado, enquanto um tenta fazer tudo certo no trabalho, o outro não se preocupa em errar, mas, ao mesmo tempo, enquanto um é muito fechado e frio, o outro é amigável e receptivo. A maleabilidade, a flexibilidade, a tranqüilidade, a amabi-lidade, a alegria e até a malandragem são características pertencentes aos brasileiros que são valorizadas, e que os nipo-brasileiros acreditam que já possuem em parte, ou que para os japoneses mais conservadores é necessário possuir.

Arriscamos afirmar que a perda de traços culturais japoneses talvez seja maior para os descendentes que moram no estado do que em outras localidades onde há mais japoneses e presença mais marcante desta cultura. Yamamoto (2000) afirma que para a manutenção de valores e costumes é importante que haja convivência e relação com membros do mesmo grupo étnico. $\mathrm{O}$ maior contato com brasileiros leva os descendentes a se abrasileirar muito mais, demonstrando maior identificação com os capixabas e, conseqüentemente, uma adaptação maior. A diferenciação entre os japoneses que moram em Vitória em comparação com os que moram em São Paulo decorre dos contextos de cidade pequena, "provinciana", e cidade grande. Algumas características atribuídas ao outro grupo (São Paulo) são negativas: são mais estressados e mais "metidos" do que os "tranqüilos" capixabas.

Identificamos também indícios de discriminação e percepção de preconceito, com prejuízo para as relações cotidianas, conforme alguns participantes, como conseqüência do estereótipo associado aos japoneses. Há um sentimento de exclusão nos ambientes em que supostamente todos os japoneses se destacam (escola, trabalho) e, em situações de competição, há a utilização de estereótipos para identificar e excluir os japoneses.

Os traços faciais são fundamentais na determinação da identidade social do grupo, assim como afirmado por Oliveira (1998). A identificação como japonês, feita pelos brasileiros a partir dos traços faciais, determina comportamentos que são esperados e leva os nipo-brasileiros a tentar manter determinadas características atribuídas aos 
japoneses, como, por exemplo, a fama de inteligentes e dedicados aos estudos e a fama de "certinhos", mesmo para aqueles que são mais identificados como brasileiros.

Como conseqüência da marcante fisionomia, os nipobrasileiros apresentam características ligadas à origem étnica, sendo cobrados tanto por suas famílias, quanto pelos brasileiros para que as mantenham. Da mesma forma, ocorre com os japoneses que residem na Grande Vitória que procuram obter destaque na educação e no trabalho, mantendo desta forma a identificação positiva de seu próprio grupo. Mais ainda, buscam uma representação positiva dos nipo-capixabas em relação aos residentes de outras localidades do Brasil. A questão da identidade social, sempre em constante metamorfose (Ciampa, 2001), é bastante clara em todo o processo de inserção e adaptação deste grupo no Brasil e na Grande Vitória, sendo ressaltadas, pelos próprios participantes, tanto as mudanças que vêm ocorrendo na comunidade japonesa, quanto as mudanças necessárias a serem estabelecidas nas suas relações cotidianas com outros grupos.

\section{Nota}

1. Se um participante possuía duas ascendências diferentes, foi considerada a geração mais próxima do issei (por exemplo, pai nissei e mãe sansei: filho nissei). Os participantes mestiços também se incluem nos dados através da descendência japonesa de um dos progenitores.

\section{Referências}

Associação Nikkei de Vitória. (1984). Imigrantes japoneses no Espírito Santo. Vitória: Associação Nikkei de Vitória.

Associação Nikkei de Vitória. (1998). Histórico da Associação Nikkei de Vitória. Vitória: Associação Nikkei de Vitória.

Bardin, L. (1994). Análise de conteúdo. Lisboa: Edições 70. (Original publicado em 1977)

Camacho, L.M.Y. (1993). As relações entre a cultura japonesa e a educação dos nipo-brasileiros: um estudo dos elementos influenciadores do desempenho escolar positivo dos descendentes de japoneses. Dissertação de Mestrado não-publicada, História e Filosofia da Educação, Pontifícia Universidade Católica de São Paulo. São Paulo, SP.

Ciampa, A.C. (2001). A história do Severino e a história da Severina: um ensaio de psicologia social. São Paulo: Brasiliense.

Ennes, M.A. (2001). A construção de uma identidade inacabada: nipo-brasileiros no interior do Estado de São Paulo. São Paulo: Ed. Unesp.

Gama Filho, O. (2003). Identidade cultural capixaba. Em F. Achiamé \& R.S. Neves (Eds.), O reino conquistado: estudos em homenagem a Renato Pacheco (pp.227-251). Vitória: Instituto Histórico e Geográfico do Espírito Santo.

Hilton, J.L. (1996). Stereotypes. Annual Review Psychology, 47 , 237-271.

Hogg, M.A.; Abrams, D.; Otten, S. \& Hinkle, S. (2004). The social identity perspective: Intergroup Relations, Self-conception and Small groups. Small Group Research, 35(3), 246-276.

Inoue, M.F.M. (2002). Do outro lado nasce o sol: o trabalho dos japoneses e seus descendentes no Estado do Rio de Janeiro. Tese de Doutorado não-publicada, Departamento de Sociologia da Universidade de São Paulo. São Paulo, SP.

Japoneses relembram a imigração. (1999, 19 de junho). A Tribuna, Cidades, p. 5.

Kitahara, S.T. (1998). Os comportadinhos na casa dos Gaijins. Em D.D. Oliveira et al. (Ed.), A Cor do Medo (pp.127-149). Brasília: Ed. UnB/Ed. UFG.
Lesser, J. (2001). A negociação da identidade nacional: Imigrantes, minorias e a luta pela etnicidade no Brasil. São Paulo: Ed. Unesp.

Morandi, A.M. (1997). Na mão da história: A CST na siderurgia mundial. Vitória: EDUFES.

Mota, E.L.A; Franco,A.L.S. \& Motta, M.C.(1999). Migração, estresse e fatores psicossociais na determinação da saúde da criança. Psicologia: Reflexão \& Crítica, 12(1), 119-132.

Nucci, P. (2000). Os intelectuais diante do racismo antinipônico no Brasil: textos e silêncios. Dissertação de Mestrado não-publicada, Departamento de História, Instituto de Filosofia e Ciências Humanas, Universidade Estadual de Campinas. Campinas, SP.

Ocada, F.K. (2000). Nos subterrâneos do modelo japonês - os 3Ks: Kitanai (sujo), Kiken (perigoso) e Kitsui (pesado). Em Anais, $12^{\circ}$ Encontro Nacional de Estudos Populacionais da Abep, 2000, Caxambu, SP. Acessado em 10/12/ 2004 de www.abep.org.br/anais2000/migração (pp.1-25).

Oliveira, A.C. (1998). Japoneses no Brasil ou Brasileiros no Japão? A Trajetória de uma Identidade em um Contexto Migratório. [1 CD]. Em Anais, 11. Encontro Nacional de Estudos Populacionais da Abep, 1998, Caxambu, SP. Belo Horizonte: ABEP

Presença amarela (1982). Presença amarela: apesar dos choques, centenas de japoneses e nisseis orientalizam o cenário capixaba. Espírito Santo Agora, 70, 10-14.

Saito, H. (Ed.) (1980). A presença japonesa no Brasil. São Paulo: Ed. da Universidade de São Paulo.

Sawaia, B.B. (2001). Identidade - uma ideologia separatista? Em B.B. Sawaia (Ed.), As artimanhas da exclusão: Análise psicos-social e ética da desigualdade social (pp.119-143). Petrópolis, RJ: Vozes.

Siqueira, S. (2005, Julho). O desenvolvimento da consciência cultural crítica como forma de combate à suposta alienação do professor brasileiro de inglês. Revista Inventário, 4. (Acessado em 28/03/2006 de http://www.inventario.ufba.br/04/04ssiqueira.htm).

Sousa, L.C. \& Santos, L. (1999). A relação entre estilos pedagógicos e desempenho escolar em Portugal. Psicologia: Reflexão \& Crítica, 12(2), 331-342.

Tajfel, H. (1983). Grupos humanos e categorias sociais: estudos em psicologia social II. Lisboa: Livros Horizonte.

Vitória será vista com outros olhos. (1974, Março). Espírito Santo Agora, 12, 30-46.

Wakisaka, K. (1989). Imigração Japonesa no Brasil: 80 anos. Estudos Afro-asiáticos, 16, 16-59.

Yamamoto, L.E. (2000). Considerações sobre a identidade étnica dos nikkeis brasileiros no Japão. Psicologia Revista, 10, 55-74.

Joyce Rumi Suda é mestre em Psicologia pela Universidade Federal do Espírito Santo. Endereço para correspondência com o autor: Av. Carlos Moreira Lima 575/301, Bento Ferreira, Vitória, ES, cep. 29050-650, Brasil. joycesuda@hotmail.com

Lídio de Souza é professor do Programa de PósGraduação em Psicologia da Universidade Federal do Espírito Santo. lidio.souza@uol.com.br

\section{Identidade social em movimento: a comunidade} japonesa na Grande Vitória (ES)

Joyce Rumi Suda \& Lídio de Souza

Recebido: 06/12/2005

$1{ }^{\text {a }}$ Revisão: 09/07/2006

Aceite final: 13/07/2006

Apoio CAPES. 